\title{
Safety of Antarctic krill (Euphausia superba) as food source: its initial fluoride toxicity study
}

\author{
Hai-Yan ZHANG ${ }^{1}$, Ming-Xiu CAO ${ }^{1,2}$, Essy Kouadio FODJO ${ }^{3}$, Cong $\mathrm{KONG}^{1,4 *}$, You-Qiong CAI ${ }^{1}$, \\ Xiao-Sheng SHEN ${ }^{1,4 *}$, Xue-Zhong CHEN $^{1}$
}

\begin{abstract}
Antarctic Krill, rich in many nutrients, is supposed to be one of the strategic food sources. However, it is not acceptable for direct consumption as traditional food, as its high content of fluoride is harmful to adults and children. Therefore, the safety of fluoride residue in Antarctic krill for food production should be investigated. In this research, the fluoride toxicity in Antarctic Krill was evaluated through mice feeding experiment. Their body weight was found not to be influenced by fluoride. However, dental fluorosis was observed in the krill group and the NaF group. Fluoride content in liver, kidney, urine, and bones are significantly different $(\mathrm{P}<0.05)$ among these three groups, which amount to plateau during the first ten days of feeding, except the fluoride in bone which keeps increasing all through the experimental time. Furthermore, less amount of fluoride was determined in the krill group compared with the amount in NaF group, even if they have the same concentration of fluoride. Besides, lesions in livers, kidneys and bones of the two experimental groups were observed through histopathological studies.
\end{abstract}

Keywords: fluoride; Antarctic krill; food safety; toxicity; polar research.

Practical Application: The different forms of fluoride in Antarctic Krill may decrease the assimilation, accumulation of fluoride in the organs and tissues. The toxicity of fluoride in food should be evaluated regarding the complex effect of different states of fluoride element and their association effect, rather than only by the free state of fluoride ion. The results may help to develop a more reliable way to access the safety of Antarctic Krill as food source, and to establish effective food safety criteria.

\section{Introduction}

Antarctic Krill rich in proteins, polyunsaturated fatty acids, minerals and large amounts of Vitamins A and E possesses the potential to be harvested with 379 million tons of total biomass and 342-536 million tons of annual gross post-larval production (Atkinson et al., 2009; Gigliotti et al., 2011). However, Antarctic Krill contains high concentrations of fluoride distribution in different tissues. Although fluoride can help to prevent dental caries and to strengthen bones in moderate contents, it can cause fluorosis disease if exist in an excessive amount in man and animals. Soevik \& Braekkan (1979) have determined the fluoride contents of $4260 \mathrm{mg} / \mathrm{kg}$ and $570 \mathrm{mg} / \mathrm{kg}$ in carapaces and muscles of Antarctic Krill. Moreover, Antarctic Krill is not acceptable for direct consumption as traditional food, as WHO recommended 2-4 mg and 1-2 mg of daily intake of fluoride for adults and children respectively.

Toxicity study of Antarctic Krill in fish has been reported in the literature. Julshamn et al. (2004) studied Atlantic Salmon feeding on diets containing krill meal (up to $350 \mathrm{mg} / \mathrm{kg}$ ) and found no fluoride accumulation within short period. Moren et al. (2007) carried out feeding trials for fishes, with krill or amphipod meals and found accumulation of fluorine in feces rather than in muscle and bone. Karlsen et al. (2006) demonstrated the indifference of muscle $\mathrm{pH}$, texture or sensory attributes in farmed Atlantic cod after the dietary inclusion of krill meal. Therefore, the krill could be used as animal feed, and meal for aquaculture. Meanwhile, Xie \& Sun (2003) found that there was no skeletal fluorosis in the bones of penguins, although their fluoride concentrations could amount to $7187 \mathrm{mg} / \mathrm{kg}$. Few researches about the toxicity of fluoride in krill to mammals are reported. Previous studies on fluoride toxicity include the subject of Fluoride contamination (Jha et al., 2011), sodium fluoride (Chattopadhyay et al., 2011; Ersan et al., 2010) and people or animals who have fluorosis diseases (Brearley \& Storey, 1970). Some scholars concluded that Antarctic Krill consists of several forms of fluoride, but its toxicity has been controversial in general. The complexed or other forms (organic or inorganic) can exert different effect on human body if it is consumed as food. Up to date, there is no special research to clarify the different toxic effect between the fluoride in Antarctic krill and the free fluoride ion (F-), when it is processed into food. Therefore, bearing this in mind, study on this subject was conducted in this work. The fluoride toxicity in

${ }^{1}$ East China Sea Fisheries Research Institute, Chinese Academy of Fishery Sciences, Shanghai, China

${ }^{2}$ College of Food Science and Technology, Shanghai Ocean University, Shanghai, China

${ }^{3}$ Laboratory of Physical Chemistry, Felix Houphouet Boigny University, Abidjan, Cote d'Ivoire

${ }^{4}$ Key Laboratory of East China Sea Fishery Resources Exploitation, Ministry of Agriculture and Rural Affairs, East China Sea Fisheries Research Institute, Chinese Academy of

Fishery Sciences, Shanghai, China

*Corresponding author: shenxs@ecsf.ac.cn, kongc@ecsf.ac.cn 
Antarctic krill is studied by feeding into mice and compared to the free fluoride ion $(\mathrm{F})$, which can help to evaluate the safety of Antarctic-krill-derived food.

\section{Materials and methods}

\subsection{Experimental animals}

The mice in this study were bred in the Experimental Animal Center, the Second Military Medical University. Normal feeding was given for seven days to adapt the mice to the environment before the experiment. All animal experiments were conducted in compliance with the guidelines of the Care and Use of Laboratory Animals. Animals were fed in a Specific Pathogen Free (SPF) grade room. Room lights were controlled to provide 12 hours of light and 12 hours of dark alternatively. All animals were supplied with sufficient food and water in the East China Sea Fisheries Research Institute (Xiaosheng Shen's group).

\subsection{Preparation of Antarctic krill powder}

Antarctic Krill were obtained from Dalian Ocean Fishery Group of Corporations (China). Antarctic Krill were frozen on-board immediately following the fish and stored at $-30{ }^{\circ} \mathrm{C}$ for about 30 days in the East China Sea Fisheries Research Institute (Xiaosheng Shen's group). These krill blocks were freeze-dried at $-106^{\circ} \mathrm{C}$ (Heto Power dry LL1500 Freeze Dryer, Thermo Scientific Co, Ltd, USA), homogenized and packed in plastic bags, and then stored at $-40{ }^{\circ} \mathrm{C}$.

\subsection{Determination of fluoride in Antarctic krill and mice organs}

$0.5 \mathrm{~g}$ sample in a $50 \mathrm{~mL}$ volumetric flask was digested with $8 \mathrm{~m} \mathrm{~L} 1: 11(\mathrm{v} / \mathrm{v})$ hydrochloric acid (36\% in weight, AR, Sinopharm Chemical Reagent Co. Ltd. Shanghai) solution at $40{ }^{\circ} \mathrm{C}$. After 1 hour, the solution was diluted to $50 \mathrm{~mL}$ with deionized water. And then the sample solution was transferred to a centrifuge tube and centrifuged at $5{ }^{\circ} \mathrm{C}(5000 \times \mathrm{g}, 10 \mathrm{~min})$. The supernatant was filtered with $0.22 \mu \mathrm{m}$ filter and further pass through the IC-Ag column to remove $\mathrm{Cl}$. Finally, the solution was stored in $10 \mathrm{~mL}$ air-tight plastic tubes before Ionic Chromatographic analysis.

Prepared samples were performed on Ionic Chromatography (850 Professional IC, Metrohm) with a Metrosep Anion Dual-2 analytical column $(20 \mathrm{~mm} \times 4 \mathrm{~mm})$. A solution containing a mixture of $5.0 \mathrm{mM} \mathrm{Na}_{2} \mathrm{CO}_{3}$ and $0.3 \mathrm{mM} \mathrm{NaOH}$ flowing at a rate of $0.8 \mathrm{~mL} \mathrm{~min}^{-1}$ served as the eluent. A solution of $20 \mathrm{mM}$ $\mathrm{H}_{2} \mathrm{SO}_{4}$ was used as the regenerant. The volume of the sample injection loop was $20 \mu \mathrm{L}$.

\subsection{Preparation of experimental feed}

The basal feed was provided by the Experimental Animal Center, The Second Military Medical University. The control group were fed with a basal diet, the krill group were fed with basal diet mixed with Antarctic Krill powder (133.9 mg/kg F-), and the sodium fluoride (GR, Sinopharm Chemical Reagent Co. Ltd. Shanghai) treatment group ( $\mathrm{NaF}$ group) were fed with the basal diet with added $\mathrm{NaF}(133.9 \mathrm{mg} / \mathrm{kg} \mathrm{F}-)$. The fluoride content in the diet is $133.90 \mathrm{mg} / \mathrm{kg}$ and per $3 \mathrm{~g}$ of the diets contains fluoride of 1/5 LD50 (Mohammed et al., 2016; She et al., 2015). All the feeds were sterilized at $121{ }^{\circ} \mathrm{C}$ for 30 minutes before taken to barrier system.

In these experiments, all the diets are taken by mice freely. Every morning, the mice were given enough diets $(30 \mathrm{~g}$ for each cage, ten mice each cage) on the steel fence cover for all-day eating, and also all the feed was eaten up in each group.

\subsection{Sub-chronic toxicity}

Ninety six-week-old ICR mice weighing between 18-22 g were randomly divided into three groups ( 15 males and 15 females). The study lasted for 30 days. Indexes record including teeth observation, body weight, absolute organ weights and relative organ weights, fluoride content, and histopathology were conducted after 10, 20, and 30 days respectively. Immunohistochemistry analysis was taken on the $30^{\text {th }}$ day.

\section{Teeth observation}

Teeth of the mice in the three groups were observed after 10,20 , and 30 days of feeding. The descriptive criteria and scoring was conducted according to the method reported by Everett et al. (2009). All mice were uniquely identified, and the examiner, who is blind of the allocation of each mouse, conducted an independent assessment on the dental fluorosis (DF) for each animal according to the criteria. The determination of DF was made clinically over the entire lower incisor tooth surfaces.

\section{Effect on body weight and organs weight}

Body weights of each group were recorded every ten days, and then these mice were killed by dislocation of cervical spine. Toxicological studies compiled with the Animal Welfare Act (United States Department of Agriculture, 1985). Organs (lungs, hearts, livers, and kidneys) were weighed to calculate Relative Organ Weight (ROW) every ten days. After then the sampled liver and kidney were kept for fluoride and histopathological analysis. ROW was calculated with the following equations: Relative Organ Weight (\%) = Absolute organ weight (g)/Body weight $(\mathrm{g})^{\star} 100$ (Kociba et al., 1978; Zaoui et al., 2002).

\section{Sample for fluoride analysis of organs}

Each Liver and kidney were divided into two parts, for fluoride and histopathological analysis respectively. Urine samples were collected using metabolic cages (one mouse per cage), at the day before determination. Blood was obtained by retro-orbital puncture using capillary tubes. Livers, kidneys, muscle, blood, urine and bones obtained from the three groups on days 10, 20, and 30 were collected for fluoride analysis.

\section{Histopathological and immunohistochemical analysis}

Livers, kidneys and bones were fixed with a $10 \%$ formalin buffered solution, washed with water and dehydrated by dehydrator (JJ-12J,Wuhan Junjie Electronics Co. Ltd, China). And then, these organ samples were embedded in paraffin blocks(JB-P5, Wuhan Junjie Electronics Co. Ltd, China), sectioned with a Pathologic 
microtome (RM2016, Shanghai Leica Instrument Co., Ltd, China). Slides were prepared and stained by hematoxylin-eosin (HE) for pathology analysis under light microscopy (Nikon Eclipse CI, Japan) (Ersan et al., 2010). These prepared bone slides were also used for immunohistochemistry analysis. Primary antibody and secondary antibody were incubated on these slides to target the cartilage alpha- 3 chain of type IX collagen. Expression of cartilage alpha-3 chain of type IX collagen was quantified through integral optical density (IOD) of each graph analyzed with Image pro-plus 6.0.

\section{Statistical analysis}

Results were expressed by means and standard deviations. Statistical analysis was performed on the SPSS statistical package 17.0 (SPSS Inc. Chicago, IL). Data was subjected to univariate analysis of the General Linear Model procedure. If significant difference between group variances was found for a given parameter, inter-group comparisons of the parameter were carried out with Duncan test. P-values of no more than 0.05 were considered as a significant difference during the comparison.

\section{Results and discussion}

\subsection{Effect on teeth}

This observation on the teeth of mice was carried out to examine the effect of fluoride after feeding with Antarctic Krill. No difference was observed on the teeth of the mice in the control group before and after the feeding experiment, so their scores are all zeros. According to standards described by Everett, teeth in the two experimental groups showed mild clinical symptoms of fluorotic incisor enamel, and their score was evaluated and showed as means and standard deviations in Table 1. During the first 10 days of feeding, only few of mice in the two groups grow into fluorotic incisor enamel with slight symptoms. And after 30 days of feeding, most of these mice showed mild characterization of fluoride teeth. However, the krill group always scored less than those of the NaF group when compared in total average. This weak effect of fluoride on mice teeth may indicate that only slight of fluoride is accumulated during the short feeding period.

\subsection{Effect on body weight and organ weight}

The change of body weight and organs (lung, heart, liver, and kidney) weight for mice in the three groups are shown in Table 2. The body weight of mice in the three groups keep increasing during the 30 -days feeding experiment. The mice

Table 1. Evaluation of the appearance of fluorotic incisor enamel in mice.

\begin{tabular}{cccc}
\hline & Control group & Krill group & NaF group \\
\hline Day 0 & 0 & 0 & 0 \\
Day 10 & 0 & $0.3 \pm 0.02$ & $0.45 \pm 0.03$ \\
Day 20 & 0 & $0.6 \pm 0.03$ & $0.8 \pm 0.02$ \\
Day 30 & 0 & $0.9 \pm 0.02$ & $1.2 \pm 0.8$ \\
\hline
\end{tabular}

All values are means \pm SD (standard deviation) for 10 mice. in $\mathrm{NaF}$ group has never shown significant difference in weight compared to the mice of the other two groups. In addition, the krill group shows no differences from the control group. Statistical analysis of these data from different groups has shown no difference during comparison between the different groups at the same feeding time. The result indicates no influence of fluoride on body weight of mice, regardless of the fluoride in the krill group or spiked directly by adding $\mathrm{NaF}$.

Table 2 shows absolute organ weight and relative organ weight of the three groups in this sub-chronic toxicity study. Although their absolute weight changed following the feeding time, there are no consistent trends for these evolutions. It can be seen that the lungs, hearts, livers and kidneys did not exhibit obvious change in terms of their relative organ weight. Statistical analysis of these data from different groups displays no difference during the comparison between the relative weight from different groups or different feeding times. These results imply that the feeding of NaF, regardless of the origin from Antarctic Krill or $\mathrm{NaF}$ compound, does not affect the weight of mice for this experimental period.

\subsection{Fluoride accumulation in different organs and tissues}

Table 3 shows the fluoride content in different organs and tissues. Fluoride contents in liver, kidney urine, muscle and blood of the three groups are significantly different. However, no apparent change in the fluoride contents in these organs and tissues was found following the feeding time in the same groups. This may indicate that fluoride had been accumulated during the initial 10 days of feeding and keep stable in the subsequent feeding.

In the bone of the three groups, fluoride showed significant differences $(\mathrm{P}<0.05)$ following the time evolution. The contents of fluoride increase with longer feeding time in the same group. And the $\mathrm{NaF}$ group always shows the highest contents of fluoride in the bone, and followed by the Krill group and the control group. These results demonstrate that the Fluoride is mainly accumulated in bones. The fluoride content tends to be stable when it reaches a sufficient level, since it increased at the first 20 days but no increase in the last 10 days. Similar results was reported by Yoshitomi et al. (2006) who applied krill (Euphausia superba) meal as a partial replacement for fish meal in rainbow trout (Oncorhynchus mykiss) diets, and concluded that accumulation of fluoride in vertebral bones inhibits the growth of their vertebral bones.

Overall, the fluoride contents in these organs or tissues are always higher in the $\mathrm{NaF}$ group than those in the Krill group, even if the mice were fed with the same concentration of $\mathrm{NaF}$, except the different way of preparation of the feed. One was prepared by adding a given amount of Antarctic Krill powder with the total fluoride of $1916.3 \mathrm{mg} / \mathrm{kg}$; the other feed was prepared directly by adding the $\mathrm{NaF}$ solution. The less extent of accumulation of fluoride in the krill group than that of the $\mathrm{NaF}$ group may be attributed to two factors. Firstly, fluoride in the Antarctic Krill powder exists in different forms (at least the associated and unassociated state), some of them are less-toxic or non-toxic, comparing to free fluoride. Some 
Table 2. Absolute (g) and relative (\%) organ weights in mice of sub-chronic toxicity study.

\begin{tabular}{|c|c|c|c|c|c|c|c|c|c|c|}
\hline & \multicolumn{3}{|c|}{ Day10 } & \multicolumn{3}{|c|}{ Day20 } & \multicolumn{3}{|c|}{ Day30 } \\
\hline & & $\begin{array}{l}\text { Control } \\
\text { group }\end{array}$ & $\begin{array}{c}\text { Krill } \\
\text { group }\end{array}$ & $\begin{array}{c}\text { NaF } \\
\text { group }\end{array}$ & $\begin{array}{c}\text { Control } \\
\text { group }\end{array}$ & $\begin{array}{l}\text { Krill } \\
\text { group }\end{array}$ & $\begin{array}{l}\text { NaF } \\
\text { group }\end{array}$ & $\begin{array}{c}\text { Control } \\
\text { group }\end{array}$ & $\begin{array}{c}\text { Krill } \\
\text { group }\end{array}$ & $\begin{array}{l}\text { NaF } \\
\text { group }\end{array}$ \\
\hline \multicolumn{2}{|c|}{ Body Weight } & $30.6 \pm 1.765$ & $30.2655 \pm 1.505$ & $30.23 \pm 1.18$ & $33.06 \pm 1.48$ & $33.39 \pm 1.09$ & $31.75 \pm 2.04$ & $35.58 \pm 1.86$ & $33.99 \pm 2.31$ & $33.04 \pm 2.33$ \\
\hline \multirow[t]{2}{*}{ Lung } & A & $0.2 \pm 0.01$ & $0.24 \pm 0.01$ & $0.24 \pm 0.015$ & $0.275 \pm 0.02$ & $0.27 \pm 0.01$ & $0.235 \pm 0.03$ & $0.27 \pm 0.03$ & $0.275 \pm 0.02$ & $0.265 \pm 0.02$ \\
\hline & $\mathrm{R}$ & $0.675 \pm 0.015$ & $0.775 \pm 0.015$ & $0.77 \pm 0.01$ & $0.85 \pm 0.03$ & $0.78 \pm 0.01$ & $0.745 \pm 0.03$ & $0.765 \pm 0.14$ & $0.78 \pm 0.18$ & $0.845 \pm 0.03$ \\
\hline \multirow[t]{2}{*}{ Heart } & A & $0.2 \pm 0.015$ & $0.225 \pm 0.015$ & $0.21 \pm 0.015$ & $0.215 \pm 0.04$ & $0.24 \pm 0.02$ & $0.225 \pm 0.03$ & $0.25 \pm 0.02$ & $0.24 \pm 0.01$ & $0.25 \pm 0.02$ \\
\hline & $\mathrm{R}$ & $0.655 \pm 0.01$ & $0.71 \pm 0.025$ & $0.69 \pm 0.025$ & $0.675 \pm 0.1$ & $0.685 \pm 0.05$ & $0.72 \pm 0.07$ & $0.705 \pm 0.07$ & $0.675 \pm 0.04$ & $0.75 \pm 0.03$ \\
\hline \multirow[t]{2}{*}{ Liver } & A & $1.485 \pm 0.145$ & $1.615 \pm 0.055$ & $1.5 \pm 0.055$ & $1.9 \pm 0.04$ & $1.995 \pm 0.05$ & $1.805 \pm 0.05$ & $2.065 \pm 0.14$ & $2.115 \pm 0.07$ & $1.805 \pm 0.13$ \\
\hline & $\mathrm{R}$ & $5.01 \pm 0.235$ & $5.115 \pm 0.09$ & $4.91 \pm 0.155$ & $5.94 \pm 0.07$ & $5.855 \pm 0.12$ & $5.885 \pm 0.36$ & $5.965 \pm 0.13$ & $6.12 \pm 0.43$ & $5.74 \pm 0.19$ \\
\hline \multirow[t]{2}{*}{ Kidney } & A & $0.585 \pm 0.065$ & $0.535 \pm 0.02$ & $0.535 \pm 0.04$ & $0.64 \pm 0.03$ & $0.655 \pm 0.04$ & $0.595 \pm 0.02$ & $0.645 \pm 0.04$ & $0.665 \pm 0.01$ & $0.515 \pm 0.03$ \\
\hline & $\mathrm{R}$ & $1.975 \pm 0.125$ & $1.68 \pm 0.035$ & $1.735 \pm 0.04$ & $1.99 \pm 0.08$ & $1.835 \pm 0.08$ & $1.92 \pm 0.06$ & $1.825 \pm 0.14$ & $1.88 \pm 0.11$ & $1.625 \pm 0.03$ \\
\hline
\end{tabular}

All values are means $\pm \mathrm{SD}$ for 10 mice. $\mathrm{A}=$ absolute organ weight $(\mathrm{g}) ; \mathrm{R}=$ relative organ weight $(\%)$.

Table 3. Fluoride content in different organs and tissues.

\begin{tabular}{|c|c|c|c|c|c|c|c|c|c|}
\hline \multirow[t]{2}{*}{ Target } & \multicolumn{3}{|c|}{ Day10 } & \multicolumn{3}{|c|}{ Day20 } & \multicolumn{3}{|c|}{ Day30 } \\
\hline & $\begin{array}{l}\text { Control } \\
\text { group }\end{array}$ & $\begin{array}{c}\text { Krill } \\
\text { group }\end{array}$ & $\begin{array}{l}\mathrm{NaF} \\
\text { group }\end{array}$ & $\begin{array}{c}\text { Control } \\
\text { group }\end{array}$ & $\begin{array}{c}\text { Krill } \\
\text { group }\end{array}$ & $\begin{array}{l}\mathrm{NaF} \\
\text { group }\end{array}$ & $\begin{array}{c}\text { Control } \\
\text { group }\end{array}$ & $\begin{array}{c}\text { Krill } \\
\text { group }\end{array}$ & $\begin{array}{l}\mathrm{NaF} \\
\text { group }\end{array}$ \\
\hline Liver (mg/kg) & $0.31 \pm 0.02$ & $0.57 \pm 0.14$ & $1.94 \pm 0.37$ & $0.42 \pm 0.09$ & $0.54 \pm 0.12$ & $1.95 \pm 0.37$ & $0.37 \pm 0.04$ & $0.63 \pm 0.15$ & $2.08 \pm 1.35 c$ \\
\hline Kidney $(\mathrm{mg} / \mathrm{kg})$ & $1.23 \pm 0.17$ & $1.47 \pm 0.27$ & $1.71 \pm 0.18$ & $1.22 \pm 0.26$ & $1.53 \pm 0.32$ & $1.71 \pm 0.11$ & $1.37 \pm 0.38$ & $1.45 \pm 0.24$ & $1.72 \pm 0.48$ \\
\hline Urine $(\mathrm{mg} / \mathrm{L})$ & $8.25 \pm 1.33$ & $32.5 \pm 3.78$ & $45.46 \pm 4.67$ & $7.06 \pm 1.21$ & $31.93 \pm 3.47$ & $44.6 \pm 3.22$ & $8.73 \pm 1.45$ & $33.89 \pm 4.12$ & $46.73 \pm 4.11$ \\
\hline Bone (mg/kg) & $19.04 \pm 4.32$ & $48.01 \pm 7.87$ & $78.33 \pm 3.11$ & $31.1 \pm 9.20$ & $63.01 \pm 7.33$ & $88.19 \pm 13.3$ & $27.39 \pm 1.91$ & $71.02 \pm 13.74$ & $100.74 \pm 8.03$ \\
\hline
\end{tabular}

All values are means \pm SD for 10 mice.

literatures reported the different portion of organic fluoride in the Antarctic Krill powder, and its distribution in different organs or tissues (Soevik \& Braekkan, 1979). Secondly, the different state of fluoride may be assimilated by varying percentages, and further result in the different contents of fluoride in the two groups.

This clue reveals that the toxicity of fluoride in food should be comprehensively evaluated through the different states of fluoride element and the association effect. However, currently, except the association with the calcium phosphate or with other inorganic mineral elements in the bone or teeth tissues (Everett, 2011; Mousny et al., 2008), the forms of fluoride in the organisms are not quite clear yet.

\subsection{Histopathological and immunohistochemical analysis}

It is found that Fluoride in the two experimental groups (the mice of the krill group and $\mathrm{NaF}$ group) cause damage to the liver, contrasting with the control group. However, liver from $\mathrm{NaF}$ group shows worse status than those from krill group (Figure 1: A1, A2, and A3). The damage displays edematous (black arrows in the graph) of liver cells and inflammatory cells infiltration (red arrows in the graph). Ersan et al. (2010) studied chronic fluorosis in the liver of mice and found hyperemia, local necrosis, hydropic degeneration, vacuolar degenerations, and swelling on hepatocytes around the central vein. Chattopadhyay et al. (2011) found fluoride induced vacuolar degeneration, micro-necrotic foci in the hepatocytes, and hepatocellular hypertrophy of liver. The histopathological examination also indicates the damage of fluoride to kidneys in two experimental groups (Figure 1: B1, B2, and B3). The kidney showed edematous of partial renal tubular epithelial cells (black arrows in the graph), ballooning degeneration and local necrosis of partial glomerulus (red arrows in the graph). Chattopadhyay et al. (2011) found that fluoride-induced kidney abnormality includes blood filled spaces, disintegration of tubular epithelium, and atrophy of glomeruli.

In combination with the data of fluoride contents in mice, it may be concluded that fluoride accumulates and causes damages in liver and kidney in early period, and keep stable even under continuous exposure to fluoride, and that fluoride is excreted with urine.

The time of demineralization in the two experimental groups is found to be significantly longer than those of the control group in the histopathological analysis (Figure 1: C1, C2, and C3). Photomicrograph of bone showed that fluoride caused damage to bones including synovial hyperplasia, inflammatory cell infiltration, and cartilage erosion (black arrows in the graph), which may be caused by calcification or ossification of bone and the decrease of the bone density after fluoride accumulation. Histopathological analysis also indicated that $\mathrm{NaF}$ group had worse injuries. The Fluoride in the Antarctic Krill may 

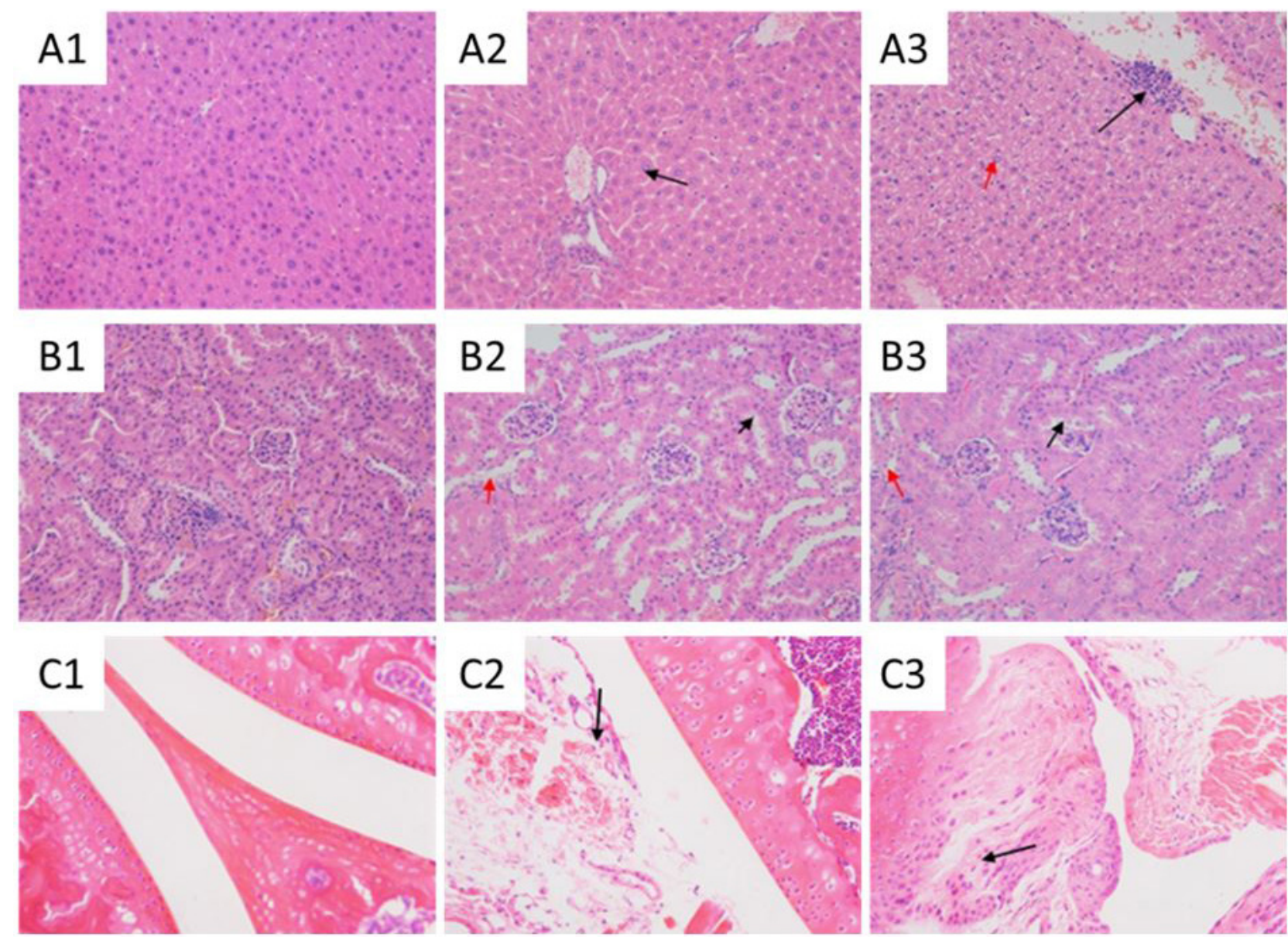

Figure 1. Photomicrograph of liver section from mice of the control group (A1), the krill group (A2) and the NaF group (A3); kidney section from mice of the control group (B1), the krill group (B2) and the NaF group (B3); bone section from mice of the control group (C1), the krill group (C2) and the NaF group (C3).

exist in a less toxic form while some other substances inside the Antarctic Krill may play an important role in reducing the toxicity of Fluoride. Reduction of the bioavailability of fluoride from Antarctic Krill by calcium is possible to some extent. Our previous study has shown the positive correlation between fluoride content and $\mathrm{Mg}, \mathrm{Ca}, \mathrm{P}, \mathrm{Mn}$ and Se contents. It may be reasonable to conclude that fluoride ion is easy to be complexed with cations in the Antarctic Krill and become less toxic.

Excess fluoride would induce cartilage injuries of rats (Wolinsky et al., 1972; Yan et al., 2011). Alpha-3 chain of collagen IX has an important role in maintaining the stability of the cartilage structure (Bönnemann et al., 2000). The expression profile of alpha-3 chain of type IX collagen in the three groups is displayed in Figure 2. Statistical analysis shows that the cartilage Alpha-3 chain of type IX collagen expression of the three groups is significantly different $(\mathrm{P}<0.01)$, in which $\mathrm{NaF}$ group exhibited the highest expression, followed by the Krill group and the control group successively. The increased expression of cartilage alpha-3 chain of type IX collagen may be the stress response that remedies the cartilage injuries fluoride brought.

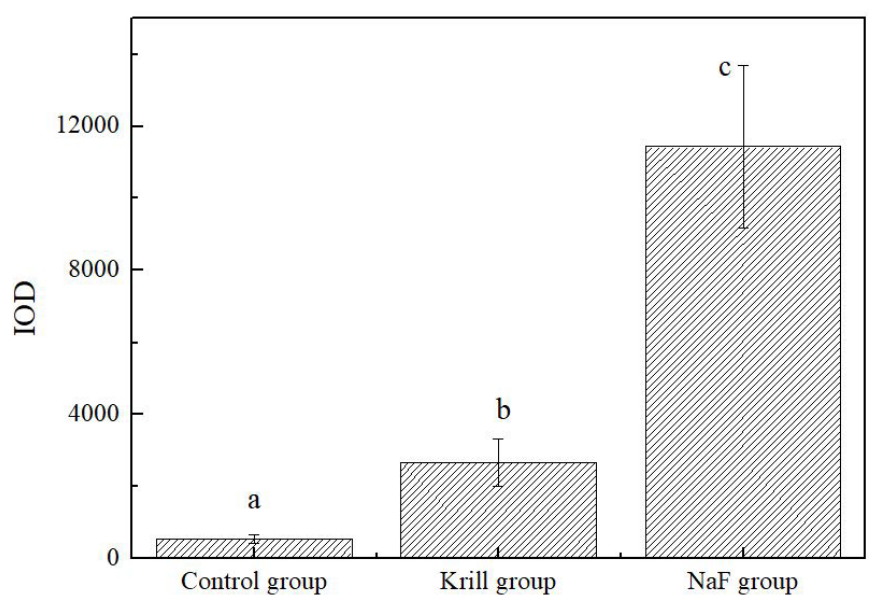

Figure 2. The expression of cartilage alpha-3 chain of type ix collagen of three groups. Data were shown an average of 5 samples with error bars.

\section{Conclusion}

In summary, the toxicity of fluoride in Antarctic Krill is evaluated by its effect on the formation of fluorotic teeth, the body weight, the organ weight, the contents in organs or 
tissues, and by histopathological and immunohistochemical inspection, when supplied to mice. Weak fluorotic formation and no obvious effect on the body weight and organ weight were found. Moreover, the results show that fluoride assimilates through blood, and is eliminated through urine, accumulates in liver, kidney, heart, muscle. This process can reach a stable state within the first 10 days of feeding. And most of the fluoride is accumulated in the bones, and is kept increasing through the whole experimental time. Fluoride in the Antarctic Krill exists in different states from free fluoride ion. These multiple fluoride forms may decrease the assimilation and accumulation of fluoride in the organs and tissues. This effect is demonstrated by the less fluoride contents in the mice of krill groups than $\mathrm{NaF}$ groups. Furthermore, histopathological analysis has demonstrated cellular lesions in livers and kidneys, and synovial damage in bones of mice. It should be noted that the potential association of impairment on bone was correlated to alpha-3 chain of type IX collagen through immunohistochemical analysis. All these results imply that the toxicity of fluoride in food should be evaluated on the complex effect of different states of fluoride element and their association effect, rather than only by the free state of fluoride ion.

\section{Acknowledgements}

We thank the financial support from National Natural Science Foundation of China (31471672), Shanghai Municipal Natural Science Foundation (17ZR1439400) and special research fund for the national non-profit institutes (East China Sea Fisheries Research Institute, No. 2011M13).

\section{References}

Atkinson, A., Siegel, V., Pakhomov, E., Jessopp, M., \& Loeb, V. (2009). A re-appraisal of the total biomass and annual production of antarctic krill. Deep-sea Research. Part I, Oceanographic Research Papers, 56(5), 727-740. http://dx.doi.org/10.1016/j.dsr.2008.12.007.

Bönnemann, C. G., Cox, G. F., Shapiro, F., Wu, J.-J., Feener, C. A., Thompson, T. G., Anthony, D. C., Eyre, D. R., Darras, B. T., \& Kunkel, L. M. (2000). A mutation in the alpha 3 chain of type ix collagen causes autosomal dominant multiple epiphyseal dysplasia with mild myopathy. Proceedings of the National Academy of Sciences of the United States of America, 97(3), 1212-1217. http://dx.doi. org/10.1073/pnas.97.3.1212. PMid:10655510.

Brearley, L., \& Storey, E. (1970). Osteofluorosis in the rabbit: macroscopic and radiographic changes. Pathology, 2(3), 231-247. http://dx.doi. org/10.3109/00313027009081212.

Chattopadhyay, A., Podder, S., Agarwal, S., \& Bhattacharya, S. (2011). Fluoride-induced histopathology and synthesis of stress protein in liver and kidney of mice. Archives of Toxicology, 85(4), 327-335. http://dx.doi.org/10.1007/s00204-010-0588-7. PMid:20859737.

Ersan, Y., Koç, E., Ari, İ., \& Karademir, B. (2010). Histopathological effects of chronic fluorosis on the liver of mice (Swiss albino). Turkish Journal of Medical Sciences, 40(4), 619-622.

Everett, E. T. (2011). Fluoride's effects on the formation of teeth and bones, and the influence of genetics. Journal of Dental Research, 90(5), 552-560. http://dx.doi.org/10.1177/0022034510384626. PMid:20929720.

Everett, E. T., Yan, D., Weaver, M., Liu, L., Foroud, T., \& Martinez-Mier, E. A. (2009). Detection of dental fluorosis-associated quantitative trait loci on mouse chromosomes 2 and 11. Cells, Tissues, Organs, 189(1-4), 212-218. http://dx.doi.org/10.1159/000151383. PMid:18701810.

Gigliotti, J. C., Davenport, M. P., Beamer, S. K., Tou, J. C., \& Jaczynski, J. (2011). Extraction and characterisation of lipids from antarctic krill (Euphausia superba). Food Chemistry, 125(3), 1028-1036. http:// dx.doi.org/10.1016/j.foodchem.2010.10.013.

Jha, S. K., Mishra, V. K., Sharma, D. K., \& Damodaran, T. (2011). Fluoride in the environment and its metabolism in humans. Reviews of Environmental Contamination and Toxicology, 211, 121-142. http://dx.doi.org/10.1007/978-1-4419-8011-3_4. PMid:21287392.

Julshamn, K., Malde, M. K., Bjorvatn, K., \& Krogedal, P. (2004). Fluoride retention of atlantic salmon (Salmo salar) fed krill meal. Aquaculture Nutrition, 10(1), 9-13. http://dx.doi.org/10.1046/j.13652095.2003.00273.x.

Karlsen, S., Suontama, J., \& Olsen, R. E. (2006). Effect of Antarctic krillmeal on quality of farmed Atlantic cod (Gadus morhua L.). Aquaculture Research, 37(16), 1676-1684. http://dx.doi.org/10.1111/ j.1365-2109.2006.01615.x.

Kociba, R., Keyes, D., Beyer, J., Carreon, R., Wade, C., Dittenber, D., Kalnins, R. P., Frauson, L. E., Park, C. N., Barnard, S. D., Hummel, R. A., \& Humiston, C. G. (1978). Results of a two-year chronic toxicity and oncogenicity study of 2, 3, 7, 8-tetrachlorodibenzo-p-dioxin in rats. Toxicology and Applied Pharmacology, 46(2), 279-303. http:// dx.doi.org/10.1016/0041-008X(78)90075-3. PMid:734660.

Mohammed, A. T., Imam, T. S., Farag, M. R., \& Ghoneim, M. H. (2016). Assessment of the toxic impacts of acute exposure to fipronil insecticide on japanese quails. The Japanese Journal of Veterinary Research, 64(Suppl. 2), S243-S249.

Moren, M., Malde, M. K., Olsen, R. E., Hemre, G. I., Dahl, L., Karlsen, Ø., \& Julshamn, K. (2007). Fluorine accumulation in atlantic salmon (salmo salar), atlantic cod (gadus morhua), rainbow trout (onchorhyncus mykiss) and atlantic halibut (hippoglossus hippoglossus) fed diets with krill or amphipod meals and fish meal based diets with sodium fluoride (naf) inclusion. Aquaculture, 269(1-4), 525-531. http:// dx.doi.org/10.1016/j.aquaculture.2007.04.059.

Mousny, M., Omelon, S., Wise, L., Everett, E. T., Dumitriu, M., Holmyard, D. P., Banse, X., Devogelaer, J. P., \& Grynpas, M. D. (2008). Fluoride effects on bone formation and mineralization are influenced by genetics. Bone, 43(6), 1067-1074. http://dx.doi.org/10.1016/j. bone.2008.07.248. PMid:18755305.

She, Y., Zhao, H., Zhu, Y., Han, Y., Xia, S., Bai, C., Zhang, J., \& Li, Y. (2015). Aluminum trichloride disorders bile acid secretion and induces hepatocyte apoptosis in rats. Cell Biochemistry and Biophysics, 71(3), 1569-1577. http://dx.doi.org/10.1007/s12013-014-0380-z. PMid:25578489.

Soevik, T., \& Braekkan, O. (1979). Fluoride in Antarctic Krill (Euphausia superba) and Atlantic Krill (Meganyctiphanes norvegica). Journal of the Fisheries Board of Canada, 36(11), 1414-1416. http://dx.doi. org/10.1139/f79-204.

United States Department of Agriculture - USDA. (1985). Food security act of 1985, subtitle $F$ - animal welfare. Washington: USDA.

Wolinsky, I., Simkin, A., \& Guggenheim, K. (1972). Effects of fluoride on metabolism and mechanical properties of rat bone. American Journal of Physiology: Legacy Content, 223(1), 46-50.

Xie, Z., \& Sun, L. (2003). Fluoride content in bones of adelie penguins and environmental media in antarctica. Environmental Geochemistry and Health, 25(4), 483-490. http://dx.doi.org/10.1023/ B:EGAH.0000004578.77543.d5. 
Yan, X., Yan, X., Morrison, A., Han, T., Chen, Q., Li, J., \& Wang, J. (2011). Fluoride induces apoptosis and alters collagen i expression in rat osteoblasts. Toxicology Letters, 200(3), 133-138. http://dx.doi. org/10.1016/j.toxlet.2010.11.005. PMid:21093551.

Yoshitomi, B., Aoki, M., Oshima, S.-i., \& Hata, K. (2006). Evaluation of krill (Euphausia superba) meal as a partial replacement for fish meal in rainbow trout (Oncorhynchus mykiss) diets. Aquaculture, 261(1), 440-446. http://dx.doi.org/10.1016/j.aquaculture.2006.06.036.

Zaoui, A., Cherrah, Y., Mahassini, N., Alaoui, K., Amarouch, H., \& Hassar, M. (2002). Acute and chronic toxicity of nigella sativa fixed oil. Phytomedicine, 9(1), 69-74. http://dx.doi.org/10.1078/09447113-00084. PMid:11924767. 